\title{
Personal indebtedness, community characteristics and theft crimes
}

\author{
Stuart McIntyre ${ }^{1}$ \\ ${ }^{1}$ Department of Economics, University of Strathclyde
}

\begin{abstract}
Debt played a central role in the Great Recession, both in its cause and in its resolution, and once again, concern is rising about household indebtedness. This paper examines the relationship between personal indebtedness and theft crime using information on personal debt default. This paper builds on an established literature examining economic conditions and community crime rates, with an analytical framework provided by the Becker (1968) and Stigler (1974). Our paper is motivated from the economic, sociology and criminology literatures, and extends to a fuller consideration of the relationship between economic hardship and theft crimes in an urban setting. In particular, the sociology and criminology literature permit a much deeper understanding of the human behaviour and motivations underpinning the relationships represented in the market model of crime. Using data available at the neighbourhood level for London, UK on county court judgments (CCJ's) granted against residents in each neighbourhood as our measure of personal indebtedness, we examine the relationship between this measure, as well as a range of community characteristics, and the observed pattern of theft crimes using spatial econometric methods. Our results confirm that theft crimes in London follow a spatial process, and that personal indebtedness is positively associated with theft crimes in London. We identify a number of interesting results, for instance that there is variation in the impact of covariates across crime types, and that the covariates which are important in explaining the pattern of each crime type are largely stable across the period considered in this analysis 11
\end{abstract}

JEL classification: R1; K42; C11; C21

Keywords: Spatial econometrics; Urban economies; Crime; Personal debt

\footnotetext{
${ }^{1}$ We are grateful to three anonymous referees for their thoughtful comments on an earlier version of this manuscript; their comments have enabled the production of a much improved manuscript.
} 


\section{Introduction}

Crutchfield (1989) argued that it is "not whether there is a relationship between economy and crime, but which economic forces affect crime rates and how?" (Crutchfield 1989, 490). Much of the literature seeking to answer this question has used unemployment as the key proxy for economic conditions (see for example: Cantor \& Land (1985), Reilly \& Witt (1992), Osborn et al. (1992), Pyle \& Deadman (1994), Elliott \& Ellingworth (1998), Carmichael \& Ward (2001) and has done so from the perspective of economics, sociology and criminology. This is the literature closest to the empirical focus of this paper. The economics literature has utilised the market model of crime framework based on the work of Becker (1968) to do so, and one of the conclusions of this literature is that an increase in unemployment ought to be associated with increases in crime, as the unemployed seek to maintain their consumption levels. Meanwhile, the sociology and criminology literature has provided a deeper framework to understand the processes and drivers of the relationship between the economy and crime. General strain theory (GST) provides the main theoretical framework for us to begin to understand the human processes which underpin the relationship represented in the market model of crime. This literature has also provided a framework which extends beyond the focus of the economics literature in understanding different types of crime.

The economics literature is premised on the proposition that increased unemployment will contemporaneously lead to increased crime; ignoring the important role, understood in the wider economics literature, of borrowing in consumption smoothing. The idea that an individual becomes unemployed and then seamlessly turns to crime as a substitute source of income, seems unrealistic. A more believable proposition, is that an individual, facing economic hardship which reduces legitimate income, would first seek to run down their savings, then would borrow money from institutional and even informal sources in order to support their current consumption, and only when their savings have been exhausted and they are liquidity constrained, might they resort to illicit sources of income to support their consumption needs. In this sense, a better theoretical predictor for the relationship between economic hardship and crime is a measure of personal indebtedness which is based on debt default.

In this paper we utilise just such a measure, and using spatial econometric methods we test the association between debt default and theft crimes in London, UK using neighbourhood data for three successive years $2^{2}$. Our model allows us to capture a range of both criminal motivation and criminal opportunity effects, as well as the important

\footnotetext{
${ }^{2}$ We do not utilise panel data spatial econometric models at this stage because of data constraints which we hope to overcome in the future. However, there are studies which use these kinds of models to examine crime rates, a recent example is Delbecq et al. (2013).
} 
role played by spatial heterogeneity within the city-region, in explaining the observed pattern of theft crimes.

The Great Recession beginning in 2008 led to an increase in unemployment, decreases in wages, and increases in debt default in many countries. In the decade prior to the 2008 recession there was a huge increase in personal debt in many countries, including in the UK3 ${ }^{3}$ and USA 4 . Since 2008 there has been a reduction in the level of outstanding consumer credit, however it had only returned to 2005 levels in the UK and 2006 levels in the USA by 2012. Given the huge increase in personal debt in the preceding decade, it is perhaps little surprise that following the start of the 2008 recession we saw an increase in personal insolvencies in the $\mathrm{UK}^{5}$ and the $\mathrm{USA}^{6}$. Against the backdrop of unprecedented levels of consumer debt and spikes in personal insolvencies, the question we address in this paper is whether there is any relationship between increases in personal debt default and increases in the number of theft crimes.

\section{Literature review}

This paper draws on three related literatures on urban crime: criminology, sociology and economics. The economics literature is used to provide an analytical framework, consistent with other works in this area, while the sociology and criminology literatures provide a deeper understanding of the observed behaviours and relationships. In this section we briefly review the main contributions of each of these literatures, with a focus on the key message of each in motivating and understanding the observed pattern of urban crime, which we draw together in the final part of this section.

\subsection{Economics literature}

Becker (1968) provides the following means of thinking about the rational offenders' decision to commit, or not, a crime. Defining $y_{0}$ as the income in the absence of any criminal activity being undertaken by the individual, the payoff from not committing crime is taken as:

$$
U_{N C}=u\left(y_{0}\right)
$$

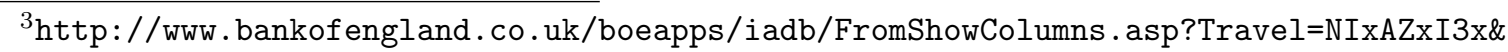
FromCategoryList=Yes\&NewMeaningId=ALONET\&CategId=6\&HighlightCatValueDisplay=Consumer\% 20 credit $\% 20-\% 20$ net $\% 20$ lending

${ }^{4}$ https://www.newyorkfed.org/microeconomics/hhdc.html

5 https://www.gov.uk/government/statistics?departments $\% 5 \mathrm{~B} \% 5 \mathrm{D}=$ insolvency-service

6 http://www.abi.org/newsroom/bankruptcy-statistics
} 
If the individual does engage in crime they obtain income $y_{1}$ if not apprehended, tried, convicted, and given punishment $F$, and $y_{1}-F$ otherwise; the condition is imposed that $y_{1}-F \leq y_{1}$. We also need to define the probability that the individual is apprehended as $p$ (it is assumed that all individuals who are apprehended are tried, convicted, and punished with certainty). The payoff from committing the crime is therefore equal to $p \cdot\left(y_{1}-F\right)+(1-p) \cdot\left(y_{1}\right)$; giving an expected utility equal to:

$$
E U_{C}=p \cdot u\left(y_{1}-F\right)+(1-p) \cdot u\left(y_{1}\right)
$$

Crime, under this approach, will not occur (sometimes called the no-crime condition), where:

$$
U_{N C}>U_{C}
$$

Becker used this simple model to illustrate how, in the presence of a sufficiently large $F$ and subject to a couple of other conditions 5 , could be very low and crime could be eradicated. Thus costs incurred in maintaining a large $p$, for instance through law enforcement activity, could be saved. This simple model has provided the basis for a large empirical literature examining different aspects of the economics of crime, most importantly for our purposes is the literature on the relationship between unemployment and crime; since it provides the closest parallel to our discussion of the relationship between financial hardship and crime. Becker's framework provided the building blocks for the economic analysis of crime through the lens of a market model for crime, aggregating such individual decisions into a supply and demand framework for the aggregate analysis of fluctuations in crime (Stigler 1974).

There is a large literature in economics looking at the relationship between economic conditions and crime (see for example Brenner 1971, 1976, 1978), Brenner \& Harvey (1978), Cantor \& Land (1985), Elliott \& Ellingworth (1998), Pyle \& Deadman (1994), Reilly \& Witt (1992), Osborn et al. (1992), Carmichael \& Ward (2001), McIntyre \& Lacombe (2012)). Most, if not all, take their theoretical premise from the work of Becker (1968). An important strand of this literature focuses on the relationship between unemployment and crime, and there are mixed findings in this literature; some papers find this relationship to be positive (Reilly \& Witt 1992, Osborn et al. 1992, Elliott \& Ellingworth 1998, Carmichael \& Ward 2001), others find it to be negative Cantor \& Land 1985 8 ,

\footnotetext{
${ }^{7}$ These are that individuals are risk neutral or risk averse, and the possibility of sufficiently severe punishments, i.e. $F \lim \rightarrow \infty$.

8 Cantor \& Land (1985) find that the relationship between unemployment and crime is initially, and generally, negative, but for some crime types there is a lagged positive effect relating to the increase in the motivation effect.
} 
while some find no or only weak evidence to support a relationship between unemployment and crime (Pyle \& Deadman 1994).

An interesting paper in this area is Field (1990) who examined trends in aggregate crime rates for England and Wales, determining that economic conditions had a big influence on crime rates. He argued that personal consumption levels (i.e. consumption per capita) was an important predictor of crime rates. He argued that since unemployment lagged consumption, consumption was a better measure of the business cycle for explaining crime rates than unemployment. A few points are worth making about this work. Firstly, Reilly \& Witt (1992) criticised the methodological approach and subsequent conclusions of this work, arguing that a finding that adding unemployment to a regression model which already included consumption, given the obvious relationship between these two variables, was not conclusive of a lack of a role for unemployment in understanding crime rates. In addition, Reilly \& Witt (1992) note that fluctuations in personal consumption have three theoretical impacts on crime rates, as Field (1990) acknowledge, and that some of these effects have ambiguous impacts on crime rates. Secondly, in much the same manner as Field (1990) argues that unemployment lags consumption, and hence drops in consumption are a better proxy for the kinds of economic and financial distress which may drive people to engage in crime, our focus on debt default would seem to capture a similarly aggravated state of economic distress, and therefore improve upon the extant literature investigating the relationship between unemployment and crime. Finally, it is worth cautioning that in Field (1990), aggregate, i.e. England and Wales, regression models are estimated, unlike much of the unemployment-crime literature which focuses on more local or community level variations in crime rates. Given regional variations in economic cycles, this would caution against estimation of models which cannot capture local variations in economic conditions.

Just as Field (1990) identified three routes through which variations in consumption levels would affect crime rates, part of the reason why there is such a large literature examining the relationship between unemployment and crime is that increased unemployment in an area would likely impact on both sides of Becker's (1968) model. Increased unemployment reduces legitimate income, but equally increased unemployment in an area will be expected to increase the number of people at home during the day. This would likely increase the probability of detection, for at least some types of crimes, in the local area (Osborn et al. 1992). In addition, as Cantor \& Land (1985) notes, being in employment creates opportunities for individuals to engage in criminal acts. One difficulty with the Becker (1968) based market model of crime is that it fails to account for the fact that not all of those who could financially benefit from crime resort to it. This was a point recognised in Reilly \& Witt (1992) who appealed to the sociological concept of 'social 
control' (explained later) in explaining why some individuals resort to crime and others do not. A different approach was taken by Dhami \& al Nowaihi (2012) in a recent paper which considered the Becker (1968) model in the context of non-expected utility theory.

This paper is of particular interest in providing a more flexible means of thinking about the decision outlined in Equation 3 above; specifically, their extension of Becker (1968) using rank dependent utility and cumulative prospect theory. It is clear that not everyone who could financially gain from committing a crime commits that crime; the difficulty with the expected utility treatment is that it fails to reflect this. In essence, the expected utility version of the market model for crime predicts a higher crime rate than we observe. The fact that that there exists a class of utility functions which capture the behaviour of individuals in overweighting low probability events, provides a useful means of thinking about the individuals decision about whether or not to commit a crime; better reflecting the observed level of criminality.

The starting point for Dhami \& al Nowaihi (2012) in extending Becker (1968) is the introduction of a probability weighting function (pwf), which they denote $w(p)$. The pwf is used to transform the probabilities in Equation 2 from the linear in probabilities assumption of expected utility. This gives a no crime condition (Equation 3) under rank dependent expected utility as: $\Gamma(p, F)=[1-w(1-p)] u\left(y_{1}-F\right)+w(1-p) u\left(y_{1}\right) \leq u\left(y_{0}\right)$. Expected utility theory predicts a level of crime which does not accord with observed crime levels, but, by introducing probability weighting functions, we can derive a utility function which better reflects the decisions individuals make and thus a model which better reflects observed levels of crime. The popularity of non-expected utility theories of crime lies in their ability to explain why people overweight low probability events, such as the probability of getting caught committing a crim 9 . This is only part of the story though, and the argument has been made before, in relation to tax evasion, that there are reasons beyond simply overweighting the likelihood of small probability events to explain the observed level of compliance with the law ${ }^{10}$,

This work builds on the earlier work of McIntyre \& Lacombe (2012) in this area. This earlier work was much more limited in terms of its empirical focus and theoretical foundations. The work here sets this work into a clearer and deeper theoretical framework using the economic, criminology and sociology literatures to do so. In addition, the work

\footnotetext{
${ }^{9}$ In the UK the probability of being caught and charged after stealing a car has been calculated (for 2002) at around 13\%, the probability of then being convicted at around $7 \%$, the chance having been convicted of being sent to jail at around $1 \%$ and the odds that you are then sentenced to more than three months in jail at 1 in 200 (see http://www.prnewswire.co.uk/news-releases/ car-thieves-enjoy-one-in-200-chance-of-getting-away-with-it-154572235.html)

${ }^{10}$ In experimental studies (Alm et al. 1992) it has been shown that: "compliance is not always due to overweighting or to extreme risk aversion, since there is some compliance when there is no chance of detection and there is some evasion when the expected value of the evasion gamble is negative" (Alm et al. 1992, 36).
} 
here is multi-year in nature, rather than focussed on a single year of data. Further, our work here extends the covariates to enable a testing of the ideas embodied in GST. In terms of our measure of financial distress, this work improves upon McIntyre \& Lacombe (2012) in focusing on the number of debt default incidents in a community rather than the total value of debt default incidents. Given that a particular level of debt default may be associated with different numbers of incidents in different communities, and the focus of GST on 'strainful events' in motivating a resort to criminality, this focus seems more appropriate. This difference in the measurement of financial distress also enables a consideration of the role of the composition of debt default incidences by value, i.e. the share of CCJs which are for small amounts versus much larger sums of money.

In summary, to understand why personal indebtedness motivates a resort to criminality, we rely upon Dhami \& al Nowaihi's (2012) extension of the market model of crime based on Becker using the cumulative prospect theory of utility developed by Tversky \& Kahneman (1992). In addition, in our model we control for some of the 'social' factors which the literature argues are important; for instance population turnover as a proxy for the strength of social bonds. While part of the explanation for the fact that not everybody who could benefit from committing crime does so will lie in an overweighting of small probability events, another part of the explanation is related to the presence of social norms and conventions about which much has been written in the sociology literature, to which we now turn.

\subsection{Sociology \& Criminology literature}

While the economics literature, through the market model of crime, provides a good analytical framework to think about the relationship between the economy and crime, it has much less to say about the underlying human and behavioural processes underpinning these relationships. The sociology and criminology literatures provide a much better and deeper understanding of these. This section intends to explore the contribution of these literatures to demonstrate the additional insight that they can bring to our discussion of the relationship between economic distress and crime.

Sociologists, such as Box (1987), have emphasised the impact of anomie and a lack of legitimate means for advancement in explaining the decision by those in economic downturns to resort to criminality ${ }^{11}$. Box (1987) categorises the three schools of thought explaining why those experiencing economic hardship may resort to crime as: strain theory, control theory, and conflict theory. Conflict theory focuses on the role of stereotypes and profiling in driving those affected to conform with the stereotype. Strain theory and

\footnotetext{
${ }^{11}$ We are grateful to two anonymous referees for suggestions to improve our discussion of, and better centre our work into, this literature.
} 
control theory are both theories focused on explaining the individual level decision to engage in criminal activity as a function of their social relationships (Agnew 1992). The distinction being that control theory focuses on the absence of key social relationships (e.g. with parents, teachers, wider society, etc), whereas strain theory captures both positive and negative relationships and stimuli (Agnew 1992). The General Strain Theory (GST) of Agnew (1992) presents a good theoretical framework for the issues discussed here.

Agnew (1992) identified three principal types of strain in his GST which can be summarised as stemming from 1 . the failure to attain desired goals, 2 . the removal of a positively valued stimuli, and 3 . the presence of negatively valued stimuli. These categories of strain are necessarily broad, and all are not anticipated to apply in all cases. Nevertheless the presentation of Agnew (1992) provides the basis for "a theory of both "criminal involvement" and "criminal events" (Agnew 1992, 60); i.e. an explanation for both individual decisions and wider events. A central role is therefore given to 'strainful events' in explaining criminal involvement and crime rates. One example of this, building on our earlier discussion, would be those experiences- such as unemployment- which can create 'strain' in the lives of those affected; encompassing the idea that those experiencing financial difficulty become alienated from society and feel relatively deprived, leading to a resort to illicit sources of income ${ }^{12}$, GST is also entirely consistent with the broader Becker (1968) framework presented earlier, with these 'strainful' events creating an incentive to engage in illicit activities, although GST goes much deeper in terms of understanding what underpins these human processes in terms of cognition and emotion.

While the presence of such negative or positive stimuli can affect both criminal involvement and criminal events, Agnew (1992) also encompasses in his GST a role for coping, helping to explain -in part- variations in the propensity of individuals experiencing 'strainful events' to engage in criminal activities. One of those factors includes what Agnew (1992) terms 'Macro-Level Variables', which given our focus on crime events -and hence crime rates in communities- would seem most pertinent to our work. Agnew (1992) focuses on the social bonds, or more broadly a sense of community, which acts to reinforce social norms and deter a resort to criminality among those experiencing hardship. Of course the reverse holds and where social bonds are weak, it is anticipated that in response to the same hardship those residing in areas with weaker social ties will be more likely to resort to crime to augment their income. A good proxy for these social norms, and their strength in an area is the extent of population turnover. It is intuitively obvious that it is more difficult to establish social bonds and ties in an area where population

\footnotetext{
${ }^{12}$ Note that the impact of these events may vary by group or individual characteristics; for instance some groups may deal better with particular types of strain, and some groups may be more exposed to particular types of strain.
} 
turnover is higher 13 .

Much of the sociology literature emphasising social bonds does so focussing on the individual, and their social bonds rather than the ecological focus of our study. An important paper which steps this out from the micro level to the macro level, is Sampson (1988), who argues that residential mobility is: "a key barrier to community-level social organisation" (Sampson 1988, 767), and demonstrates this in his subsequent empirical work. He further identifies the key impacts of population instability in enabling fewer opportunities to establish friendships, fewer opportunities to get involved in local community activities and governance, motivating fewer attempts to establish friendship, and reducing 'individual sentiments' towards the community. In other words, some of the individual experiences which are hypothesised in the literature as determining individual criminality are in fact ecological in nature. These ecological factors also relate directly to the Becker (1968) framework in affecting the expectation of deterrence. In areas with low social ties, and a high degree of turnover in the population, the probability of detection will likely be lower. To see this, consider that in relation to housebreaking, in areas with low social ties and high population turnover it is less likely that neighbours will be surprised by the presence of strangers or willing to challenge those they do not recognise. In areas with less social chaos and disorganisation, where people know their neighbours and are consequently more likely to challenge the presence of strangers, the probability of detection, and hence $p$ in Equation 2, is expected to be greater.

The criminology literature in this area is large (see for instance Box (1987) and Cantor \& Land (1985)), and the relationship between economic downturns and crime was well summarised by Farrington et al. (1986): "unemployment causes financial hardship, which in turn causes crime designed to alleviate that hardship..." (Farrington et al. 1986, 335). A similar argument could be made about personal indebtedness, and indeed given that incurring debt may be the first stage of 'coping' for those experiencing financial hardship it is arguable that the presence of personal indebtedness represents an aggravated stage of financial hardship compared to becoming unemployed. A number of empirical studies in criminology have focussed on aggregate unemployment, however as Crutchfield (1989) argues, unemployment status doesn't comprehensively capture the process that is at work relating labour market status to crime. Introducing a "dual labour market" (Crutchfield 1989) where workers are either employed in a 'primary' or 'secondary' sector, he demonstrates that there is much more to the impact of employment and indeed unemployment on crime than whether one is in employment or not. Specifically, that the type of employment one is in, or could be in, or was in, is an important determinant of

\footnotetext{
${ }^{13}$ Chilton (1964) notes that in a study by Clifford Shaw population change and poor housing (along with $\mathrm{TB}$, adult crime rate and mental disorders) were taken to represent a measure of social disorganisation which were found to be highly correlated with levels of juvenile delinquency.
} 
many of the social elements which help us to understand variations in crime.

Crutchfield (1989) sees income as the consequence of labour market experience, but labour market experience representing much more in terms of social status and social bonds. Crutchfield (1989) focuses on social and ecological factors (such as local social ties and bonds with society) which he believes are associated with labour market status. These are the same factors which the empirical criminology literature emphasises, capturing these factors through the inclusion of information on, for instance, population turnover. The argument being that higher population turnover is representative of weaker social ties. Other factors which the criminology literature highlights include population density, which makes certain crimes riskier, for instance housebreaking, as there is an increased probability of detection. For other crimes, such as thefts from the person, the criminology literature tells us that higher population density should be associated with more of these crimes as it increases the potential victim pool.

\section{Data \& model}

Our data come from three sources, principally the UK Neighbourhood Statistics website (neighbourhood.statistics.gov.uk), but also the London Data store, and data released to us by Registry Trust Ltd. Our database covers a range of economic, crime and socioeconomic variables at the 'super-output' area level. There are two 'super-output' area levels; lower and middle, we utilise middle super output area (MSOA) data in this paper. There are 982 MSOA's in London with a minimum resident population of 5,000 people and an average of 7,200 . We analyse 5 different types of theft crime in this paper, these are: robbery, burglary of a dwelling, burglary of a non-dwelling, theft from a motor vehicle and theft of a motor vehicle. We also present the results from an 'aggregate' theft crime rate based on the total of these five offences. All crime variables are converted into crime rates (crimes per 1000 people usually resident) using population data.

We include a range of economic and socioeconomic variables to capture both the criminal motivation and criminal opportunity effects defined as important in the literature. Firstly, we control for the average level of income in the area, one would expect that on average and in general higher income areas experience fewer crimes, however since higher income areas provide a greater potential loot from house breaking, one might expect that this type of crime will be more common in higher income areas. Secondly, we control for income inequality in the area, using the ratio of mean to median incomes. One might expect that greater income inequality will increase social strain and therefore the motivation for the commission of certain types of theft crimes. Equally, however, one might expect that higher income inequality in an area would incentivise greater expenditure 
by the wealthy to prevent themselves becoming a victim of crime, and therefore may be associated with lower crime rates for particular crime types.

Thirdly, we control for the level of personal indebtedness in an area, this captures the economic hardship dimension which has been extensively emphasised in the literature, and in particular the unemployment-crime literature. We would expect that the greater the level of personal indebtedness in an area the higher the crime rate in that area, and conceivably the higher the crime rate in neighbouring areas. Fourth, we include a measure of the quality of the housing in an area, beyond capturing one element of the ease with which one could gain access to a property in the area to burglarise it, this measure also captures another element of the local environment. Fifth, we control for the age profile of the area (the more children and elderly people there are in an area, the higher the resident population is likely to be during the day and hence the higher the probability of detection) but also the gender mix ${ }^{14}$. One thing to note on our inclusion of both the share of the population which is elderly and the share of the population which is very young as capturing a deterrent effect, is that while the elderly are likely to be 'at home' or near home during the day, the young are more likely to be out and about (in many cases with parents) in the community. In other words, they suggest a slightly different scope for deterrence.

Sixth, we control for population turnover in aggregate, as a measure of the strength of social ties, and also the likelihood of detection. Areas experiencing rapidly growing populations are likely to be areas where there are a wider range of changes and disruptions taking place, manifesting themselves in weaker social bonds and (for instance) reduced suspicion of strangers, which is what this variable is seeking to capture. In addition, we include a similar measure of population turnover for those aged 16-24 years old, to capture whether this age group, which the literature identifies as being important for crimes of this nature, increased or decreased in size in that year in that area. Seventh, we include the percentage of the community which is non-white British to capture the racial/ethnic composition of the area. Finally, in line with most other studies, we include the population density of the area in order to capture one aspect of the probability of detection.

Two of our variables are only available for the middle year of our analysis (housing in poor condition and average weekly household name). This means that we are assuming that the relative values of these variables between areas in each year is the same. While the use of these variables in the previous and following years' analysis is not ideal, it is the best that can be done given that we are working at a small spatial scale 15 . In our

\footnotetext{
${ }^{14}$ One might believe, for instance, that a greater number of females in an area may increase the odds of success in committing certain types of crime.

${ }^{15}$ Note that, if one had data for a greater number of years, one could estimate a panel model using
} 
main results in this paper we specify our spatial weight matrix on the basis of contiguity. LeSage \& Pace (2014) demonstrate that the precise specification of the spatial weight matrix, i.e. contiguity, $n$ nearest neighbours, etc, makes little difference to the results obtained empirically so long as a properly specified econometrics model is estimated and the marginal effects are properly calculated using scalar summaries. In our case, we calculated our results based on weight matrix specifications other than contiguity (4-6 nearest neighbours) and our results were qualitatively unchanged. As a robustness check, Table 4 presents the result for each crime type for 2003 calculated using a model with an inverse distance based spatial weight matrix. Our results are qualitatively unchanged, although in a very few cases a variable goes from being marginally significant to marginally insignificant and vice-versa, at the $95 \%$ level of significance, but our central 'Number of CCJs' variable is never affected.

In terms of modelling strategy, there is a lively debate in the literature and the spatial econometric community about whether a general-to-specific or specific-to-general approach is the best approach. In our case we choose to go from the specific to the more general models. To do so, we estimate the three most common spatial econometric models, these are: the spatial error model (SEM) the spatial autoregressive model (SAR) and the Spatial Durbin model (SDM) (see LeSage \& Pace (2009) or Elhorst (2014) for a textbook exposition of these models). Each of these models suggests a slightly different spatial process, and hence motivation. These can be summarised as follows:

In the SAR (or spatial lag) model spatial autocorrelation is exhibited in the dependent variable. From an econometric perspective, if the true data generating process (DGP) for the data is the SAR model, and one utilizes, for example, OLS for estimation purposes, the resulting coefficient estimates will be biased and inconsistent due to the endogeneity of the term on the right hand side of the equation (LeSage \& Pace 2009). This model suggests that crime rates follow a spatial autoregressive process, and hence crime rates in one area impact on crime rates in neighbouring areas- consistent with the standard crime spillover argument. The SAR model extends the classic linear regression model through the inclusion of a lagged dependent variable, $\rho W y$, as shown in Equation 4.

$$
y=\alpha+\rho W y+\beta X+\epsilon
$$

The SEM model posits that the spatial autocorrelation is found in the error term. It is possible that for a variety of reasons, when an econometric model is specified and estimated, certain factors that should be included in the model are not and that these factors are correlated over space, resulting is residual spatial error correlation. If the true these data and still include these variables using a random effects specification. 
DGP is the SEM model and, again for example, OLS is used in the estimation, the OLS estimators of the coefficients are unbiased but inefficient and the estimates of the variance of the estimators are biased (LeSage \& Pace 2009). The SEM model closely resembles the classic linear regression model, but with spatial effects coming in through the error term with the spatial lag of $\epsilon, \lambda W \epsilon$.

$$
\begin{array}{r}
y=\alpha+\beta X+\epsilon \\
\epsilon=\lambda W \epsilon+u
\end{array}
$$

The SDM model extends the SAR model by including spatially weighted explanatory variables. LeSage \& Pace (2009) suggest that the SDM model should be used when one believes that there may be omitted variables that follow a spatial process and are correlated with included independent variables. The SDM model extends the SAR model, in Equation 4, through the inclusion of spatially weighted covariates $\theta W X$.

$$
y=\alpha+\rho W y+\beta X+\theta W X+\epsilon
$$

All models are estimated using Bayesian spatial econometric methods with diffuse, relatively uninformative priors specified. Having estimated the three spatial econometric models (SAR, SEM, SDM) we calculate posterior model probabilities to select the best fit model, the results of which we then present. All models are considered equally plausible ex-ante.

\section{Results}

Our empirical approach is to test between three possible spatial econometric models, the SAR, SEM and SDM models, selecting the best fit model using a posterior model comparison approach. We report for each year and crime type only the result from the model with the highest posterior probability. In all cases the model selected was either the SDM or SAR model, and this model was selected with a very high probability. Recall that the difference between these two models was that the SDM also included spatially weighted covariates. The model selected is indicated at the bottom of the results table for each year. Given that the SAR and SDM models have been selected in all cases, by testing the statistical significant of the coefficient on the spatial weight matrix $(\rho)$, indicated towards the bottom of each results table, we can test whether the use of spatial econometric methods is appropriate-which we find that it is in all cases.

In the results which follow we calculate $95 \%$ credible intervals, and where the interval 
does not include 0, i.e. the credible intervals have the same sign, these are considered significant at the appropriate level. Coefficients with a ${ }^{\text {'*' }}$ after them in Tables 1 - 3 are those which are considered significant at the 95\% level. Following LeSage \& Pace (2009), and as is now standard practice when reporting the results of a spatial econometric model with a lagged dependent variable, we calculate scalar summaries for all variables. This means that we report our results showing the direct, indirect and total effects. We explain this distinction more intuitively in the next section. Finally, all of the variables used in this analysis were studentized. This means, in interpreting these results, one should read the coefficient as indicating the effect of a 1 standard deviation change in the covariate as a $\beta$ standard deviation change in the crime rate.

\subsection{Empirical findings and discussion}

Tables 1 3 present the results from our spatial econometric analysis of each type of crime in London for the years 2003 to 2005. We have, as is standard in the spatial econometrics literature, calculated the direct, indirect and total effects estimates for each variable. In interpreting these results, we need to first explain the distinction between the direct and indirect effects. The direct effects are the impact of our explanatory variable in that area on our dependent variable in that area; for instance the impact of income in Shoreditch on robbery rates in Shoreditch. The indirect effect is the impact of the explanatory variable in one area, on the dependent variable in neighbouring areas; for instance the impact of income in Shoreditch on robbery rates in Bethnal Green (see LeSage \& Pace (2009) for more on this). The total effect is the sum of the direct and indirect effects.

\subsection{Robbery}

Columns 2-4 of Table 1 3 contains the regression results related to robbery rates. Firstly, note that the SAR model was selected in all years for this crime type, and the $\mathrm{R}^{2}$ is above .4 in all years. Our measure of personal indebtedness or debt default, is highly significant in all years for the direct, indirect and total effects. This suggests that the greater the number of personal indebtedness incidents in a community is, the higher the robbery rate in that community and in neighbouring communities. There does not appear to be any impact of the value composition of these debt default cases by value of the CCJ.

Higher population density has a negative direct, indirect and total effect association with robbery rates as one might expect given the implied increased risk of being caught in a more densely populated are ${ }^{16}$. The higher the share of the population that is aged

\footnotetext{
${ }^{16}$ Some of the existing literature suggests that for personal theft crimes, such as robbery, population density is positively associated with these crimes; the argument being that the higher the population
} 
0-15 years old, the lower robbery rates are. There is no impact of the share of OAPs in the population on robbery rates. Following our earlier discussion, both of these were included as capturing aspects of deterrence, with the distinction that the greater the share of young children in the community the greater the share of usually resident but mobile individuals, perhaps providing some level of deterrent to opportunistic crimes that take place in public places, compared to the elderly who are less mobile and therefore may provide a greater deterrent effect for crimes such as burglary or motor vehicle theft. This conclusion would be in line with our findings here.

The proportion of non-whites in an area is positively associated with robbery rates in all three years. Other community characteristics have the expected impact. These include the measure of poor housing which is positively associated with robbery rates (so the poorer the housing quality the higher robbery rates are) likely reflecting more widespread dilapidation of the community which provides the opportunity for robberies to take place (thinking for instance about poor quality mass social housing estates and 'tower blocks'). Income levels and income inequality are negatively associated with robbery rates. This may seem surprising at first, but on reflection makes sense. Higher income individuals may take steps to increase their personal security such as travelling by car more often, avoiding public transportation, etc.

\subsection{Thefts of motor vehicles}

Columns 5-7 of Table 13 presents our result for rates of thefts of motor vehicles. In all cases the $\rho$ coefficient is highly significant, indicating that the spatial econometric models are the appropriate modelling environment for this type of crime. In addition, we can see that the $\mathrm{R}^{2}$ from these models are all above 0.4 . Higher population density is found to be associated with fewer motor vehicle thefts, as expected. There is no significant association between the share of the population which is aged $0-15$ years old and rates of motor vehicle theft, but that there is a significant and negative association between the share of the population which is elderly and rates of motor vehicle theft. In line with our earlier discussion of the deterrent effect of different groups within the population, this seems sensible. Particularly in large cities such as London, cars are often left at or near home for extended periods of time, and as such one would expect a larger deterrent effect of the less mobile elderly population for this crime type.

In all years there is a significant and positive association between rates of motor

density the greater the potential victims. Indeed in some initial work for the North East of England region we found this relationship to be positive and significant. We will explore this issue further as part of our future activities; however looking simply at the raw data on population densities shows that the London city-region and the North East England region have vastly different scales for population density and so perhaps this offers some explanation for our different findings. 
vehicle theft in an area and personal debt default in that area. For the years 2004 and 2005 this effect also extends to a positive association with rates of motor vehicle thefts in nearby neighbourhoods. This accords with our prior expectation, and in contrast to the case of thefts from the person discussed in the previous sub-section where the effect was not as obvious and consistent, the potential 'loot' associated with a motor vehicle theft is significantly higher which perhaps explains this difference. From the results for 2004 and 2005 we can see that areas with a net inflow of young people aged 16-24 years are also areas where thefts of motor vehicles are most common, this is perhaps unsurprising given that this age range are the prime group for engaging in 'joy riding'.

Poor quality housing in an area is positive and significantly associated with thefts of motor vehicles in that area, and in the later two years also in surrounding neighbourhoods. Income in all years is negatively associated with the rate of thefts of motor vehicles, which makes sense given that higher income individuals are likely to own more expensive and more difficult to steal motor vehicles. Income inequality in an area, in the later two years, is positive and significantly associated with rates of motor vehicle thefts in that area and in neighbouring areas. Given that motor vehicles are an obvious source of conspicuous consumption, and hence in that sense emphasise inequality, this feeling of inequality may be providing a motivation for individuals in that area to engage in crime, and stealing a motor vehicle may provide a quick solution to that feeling of inequality.

\subsection{Thefts from motor vehicles}

Columns 8-10 of Table 1 -3 provides the results of our model for thefts from motor vehicles. The spatial coefficients are all highly significant. Only in 2003 is the number of CCJs significant and positively associated with rates of thefts from motor vehicles. When considered alongside our results related to robbery and motor vehicle theft rates, where numbers of debt default had a consistently positive association with these crime rates, this suggests that there is perhaps a greater impact of debt default on those crimes with, ex-ante, more lucrative potential rewards. This makes sense if one considers that the types of debts for which an individual would seek a CCJ against another would not be those which could be repaid by stealing and then pawning a mobile phone or satellite navigation system.

Population density is, as expected, negatively associated with thefts from motor vehicles, and while there is no significant impact of the share of the population which is elderly, there is a significant impact in two of the years of the share of the population which is aged 0-15 year old. This follows from our earlier discussion about the deterrent effects of the share of young children in an area in terms of a usually resident but mobile population group. Thefts from cars typically take place when vehicles are away from the 
home environment, and hence the share of the population which is usually resident and mobile would be a greater deterrent than an immobile more residential centric part of the population.

Income inequality in an area in all years is positively associated with rates of theft from motor vehicles, and in years 2004 and 2005 is also significant and positively associated with thefts from motor vehicles in surrounding neighbourhoods. Given that these crimes are very simple to commit (one only has to break a car window), and provide a quick and easy loot (satellite navigation systems, mobile phones, handbags, etc) it is perhaps no surprise that areas which are more unequal in terms of income see higher rates of this type of crime. Similarly, it is interesting to note that areas seeing higher net inflows of 16-24 year olds are also those areas with higher rates of this type of crime.

\subsection{Burglary}

For this crime type all results are contained in Columns 11-13 of Table 1-3. The spatial coefficient is highly significant in all cases. We can see that in two of the three years personal debt default is positive and significantly associated with burglary rates, as is income. The number of debt default incidents being positively associated with burglaries is in line with our expectations, and given that the potential loot from burglarising a house is likely a function of the income of the individuals living there, higher burglary rates being associated with higher income is what one would expect. The more houses in poor condition, the higher the rate of burglaries. Given that better quality housing is more difficult to break into, this is what one would expect. Where it is significant, population density exerts its usual negative effect on this crime rate. We can also see that the greater the share of the population in an area which is aged $0-15$, in all three years, and who are OAPs, in 2003 and 2004, the lower the rate of burglary in that area are. Given the emphasis that we have placed on these groups being more likely than those of working age to be at home, this suggests some kind of deterrent effect.

The greater the share of the population which is non-white, the higher rates of burglary are in all three years. This perhaps suggests that the homes of members of this community are seen to be easier targets, or perhaps targets which are less likely to cooperate with the authorities in investigating these crimes. In the alternative, it may be that members of these communities themselves engage more in this type of activity. We also see that in our 2004 and 2005 results where the 16-24 year old population is growing crimes of this type are higher. For income inequality we see that in the later two years of our analysis income inequality is negatively associated with burglary rates. In a similar manner to our earlier discussion of robbery rates, one might not expect that this more sophisticated or skilled 'higher stakes' crime would be the one that those motivated by 
material inequality would turn to to address this inequality. In addition, higher income inequality in an area may incentivise greater investment in home security, increasing the probability of detection and increasing the 'costs' of committing the burglary.

\subsection{Burglary of non-dwellings}

Columns 14-16 of Table 1-3 presents the results relating to burglary of non-dwellings. In all cases the spatial lag coefficient is highly significant ${ }^{17}$. Areas with higher incomes are found to have lower rates of non-dwelling burglary, which would make sense given that these areas are likely to have fewer non-dwellings. Population density and the percentage of the population aged 0-15 years old have the anticipated negative association with this type of crime. The more houses in poor condition, the higher the rate of nondwelling burglary. If, consistent with our earlier interpretation, we take this measure to be indicative of a more generally dilapidated environment, then one would expect that the non-dwelling properties in these areas would be of a similarly poor standard, which consistent with our results and interpretation for burglary, would be easier to burglarise. In terms of personal debt default, we can see that in all cases there is a significant and positive association between this measure of financial distress and the burglary of nondwellings. In addition, the share of these debt defaults which are valued at over $£ 1000$ is positively associated with rates of this type of crime in two of the three years. We can also see that the areas where the number of 16-24 year olds is increasing are associated with higher rates of non-dwelling burglary.

\subsection{Total theft crimes}

This final section reviews the results from what we term the rate of 'total theft crimes'. This is simply the sum of the crimes previously described per 1,000 people. These results are presented in Columns 17-19 of Table 1-3. In all cases the SDM model is selected and the spatial coefficient is highly significant. The key results from the direct effects here include: areas with a growing 16-24 year old population are areas with higher theft crime rates; areas with greater population density have lower theft crime rates, areas with more personal debt defaults have higher theft crime rates; areas with poorer quality housing have higher theft crime rates and areas with a greater proportion of the population aged 0-15 years have lower theft crime rates. For the indirect effects, the only consistent result across years is that higher population density in one area is associated with greater crime rates in neighbouring areas, perhaps suggesting some kind of displacement effect.

\footnotetext{
${ }^{17}$ Note that 'non-dwellings' is used to refer to the burglary of any vacant properties, short stay hotel rooms, industrial units, and offices.
} 


\subsection{Alternative weight matrix}

The results presented in this paper so far have all been estimated using a contiguity based weight matrix. A reasonable question would be how well a contiguity based weight matrix captures the spatial relationships in crime rates at the MSOA level within London, and might an alternative specification produce different results? We noted earlier that LeSage \& Pace (2014) showed that in a properly specified spatial econometric model, with the correct partitioning of the marginal effects into the direct, indirect and total effects, the precise specification of the spatial weight matrix (e.g. contiguity, nearest neighbour, inverse distance) made little difference to the marginal effect estimates. In order to demonstrate this general result in our case, we estimated all of our models for 2003 using an inverse distance based weight matrix. We present the results from this in Table 4. Comparing our results using this weight matrix specification we can see that our results are qualitatively unchanged. In a very few cases a variable goes from being marginally significant to marginally insignificant and vice-versa, at the $95 \%$ level of significance, but these instances are rare and our central 'Number of CCJs' variable is never affected.

\section{Conclusion}

This paper has demonstrated a number of key results. Firstly, that neighbourhood debt default is positively associated with different types of theft crimes, suggesting that economic and financial hardship in communities has an important role to play in explaining local crime rates. Secondly, this paper has demonstrated, statistically, the important role of spatial spillovers in understanding crime rates in an urban setting. Thirdly, we have been able through our covariate choice to test the ideas of the sociology and criminology literature around the strength of social ties, demonstrating the contribution and insight of GST in explaining urban crime rates. Fourthly, we have seen that our results are broadly consistent across the three years studied here, adding strength to our conclusions. Finally, we have seen that our spatial econometric results are robust to changes in the specification of the spatial weight matrix. Household debt is once again on the rise, and when the next recession does come, as it surely will, indebted households may struggle to avoid defaulting on those debts. What the results here suggest is that increases in debt default in neighbourhoods impose a significant social cost on that neighbourhood and in neighbouring areas through increases in theft crimes. Policymakers would do well to recognise the need to support financially vulnerable communities, to lessen the likelihood of financial distress and default, and in doing so preventing significant social costs being imposed on communities. 


\section{References}

Agnew, R. (1992), 'Foundation for a generalism strain theory of crime and delinquency', Criminology 30, 47.

Alm, J., McClelland, G. H. \& Schulze, W. D. (1992), 'Why do people pay taxes?', Journal of Public Economics 48(1), 21-38.

Becker, G. (1968), 'Crime and Punishment: An Economic Approach', The Journal of Political Economy 76(2), 169-217.

Box, S. (1987), Recession, crime and punishment, Macmillan Education, London.

Brenner, H. (1978), Impact of economic indicators on crime indices, in 'Unemployment and Crime', United States Congress.

Brenner, M. (1971), Time series analysis of relationships between selected economic and social indicators, Dept. of Epidemiology and Public Health, Yale School of Medicine.

Brenner, M. (1976), Estimating the social costs of national economic policy: Implications for mental and physical health, and criminal aggression, Johns Hopkins University, School of Hygiene and Public Health and Dept. of Social Relations.

Brenner, M. \& Harvey, M. (1978), 'Economic crises and crime', Crimes and society pp. $555-72$.

Cantor, D. \& Land, K. (1985), 'Unemployment and crime rates in the post-World War II United States: A theoretical and empirical analysis', American Sociological Review pp. 317-332.

Carmichael, F. \& Ward, R. (2001), 'Male unemployment and crime in England and Wales', Economics Letters 73(1), 111-115.

Chilton, R. (1964), 'Continuity in delinquency area research: a comparison of studies for Baltimore, Detroit, and Indianapolis', American Sociological Review pp. 71-83.

Crutchfield, R. D. (1989), 'Labor stratification and violent crime', Social Forces 68(2), 489-512.

Delbecq, B., Guillain, R. \& Legros, D. (2013), 'Analysis of crime in Chicago: new perspectives to an old question using spatial panel econometrics', Discussion Paper, Regional Research Institute, West Virginia University, available at: http://www.rri.wvu.edu/wp-content/uploads/2013/07/Fullpaper_5.B.1.pdf. 
Dhami, S. \& al Nowaihi, A. (2012), 'An extension of the becker proposition to nonexpected utility theory', Mathematical Social Sciences .

Elhorst, J. P. (2014), Spatial econometrics: from cross-sectional data to spatial panels, Springer.

Elliott, C. \& Ellingworth, D. (1998), 'Exploring the relationship between unemployment and property crime', Applied Economics Letters 5(8), 527-530.

Farrington, D., Gallagher, B., Morley, L., St Ledger, R. \& West, D. (1986), 'Unemployment, school leaving, and crime', British Journal of Criminology 26(4), 335.

Field, S. (1990), Trends in crime and their interpretation: A study of recorded crime in post war England and Wales, HM Stationery Office.

LeSage, J. P. \& Pace, R. K. (2009), Introduction to Spatial Econometrics, CRC Press, Boca Raton, FL.

LeSage, J. P. \& Pace, R. K. (2014), 'The biggest myth in spatial econometrics', Econometrics 2(4), 217-249.

McIntyre, S. G. \& Lacombe, D. J. (2012), 'Personal indebtedness, spatial effects and crime', Economics Letters 117(2).

Osborn, D., Trickett, A. \& Elder, R. (1992), 'Area characteristics and regional variates as determinants of area property crime levels', Journal of Quantitative Criminology 8(3), 265-285.

Pyle, D. \& Deadman, D. (1994), 'Crime and unemployment in Scotland: some further results', Scottish Journal of Political Economy 41(3), 314-324.

Reilly, B. \& Witt, R. (1992), 'Crime and unemployment in Scotland: an econometric analysis using regional data', Scottish Journal of Political Economy 39(2), 213-228.

Sampson, R. J. (1988), 'Local friendship ties and community attachment in mass society: A multilevel systemic model', American Sociological Review pp. 766-779.

Stigler, G. J. (1974), The optimum enforcement of laws, in 'Essays in the Economics of Crime and Punishment', NBER, pp. 55-67.

Tversky, A. \& Kahneman, D. (1992), 'Advances in prospect theory: Cumulative representation of uncertainty', Journal of Risk and uncertainty 5(4), 297-323. 


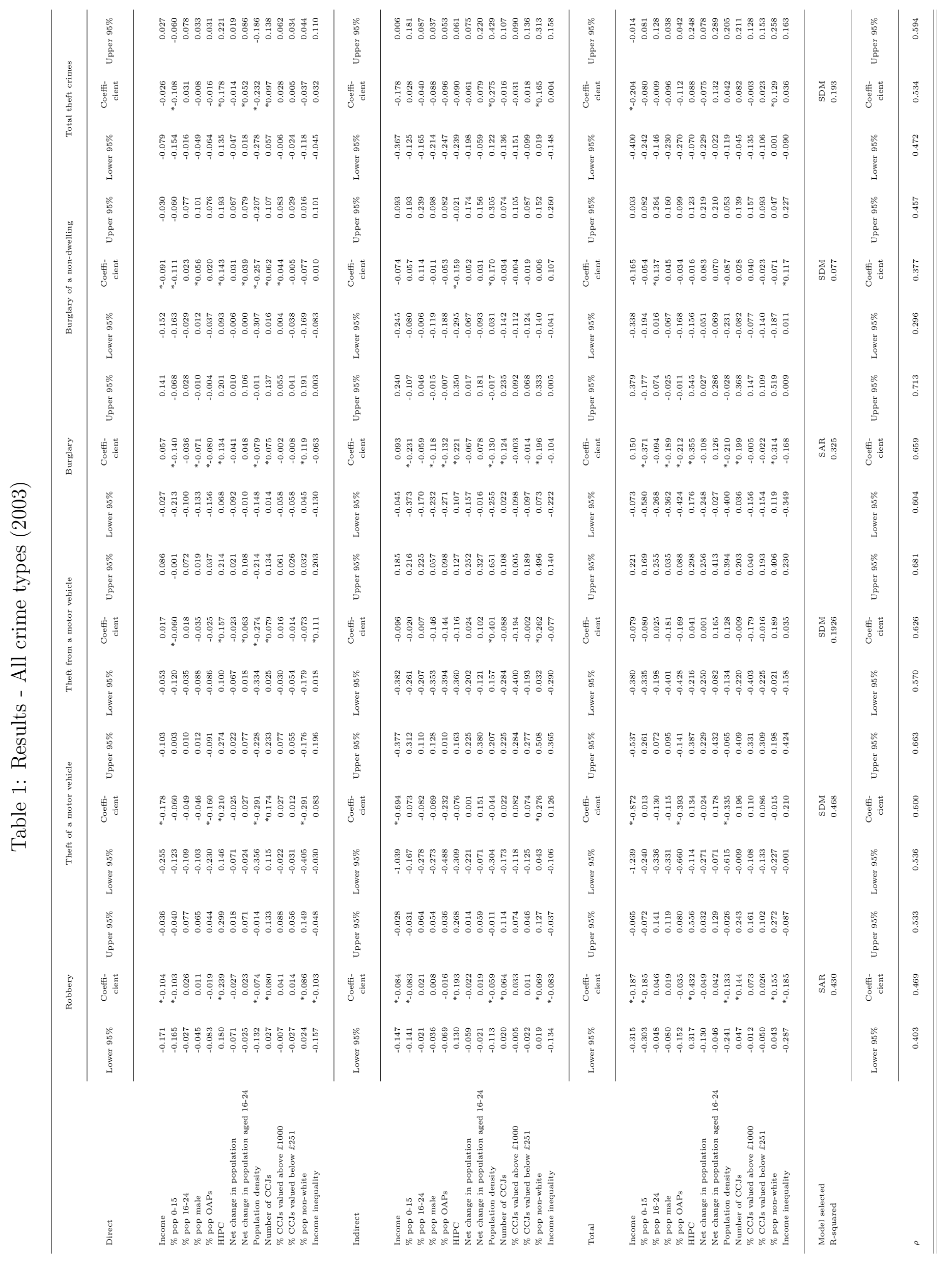




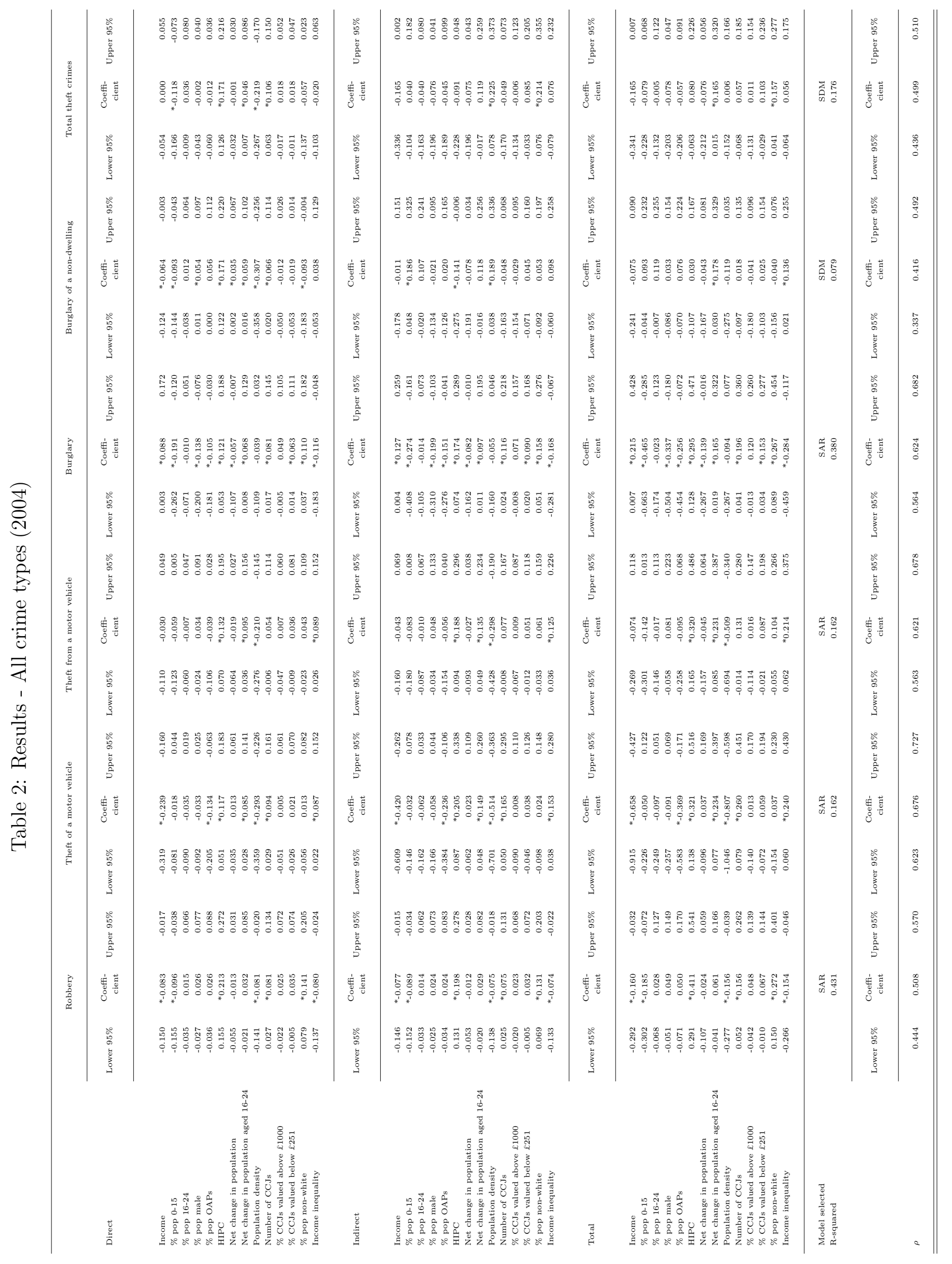




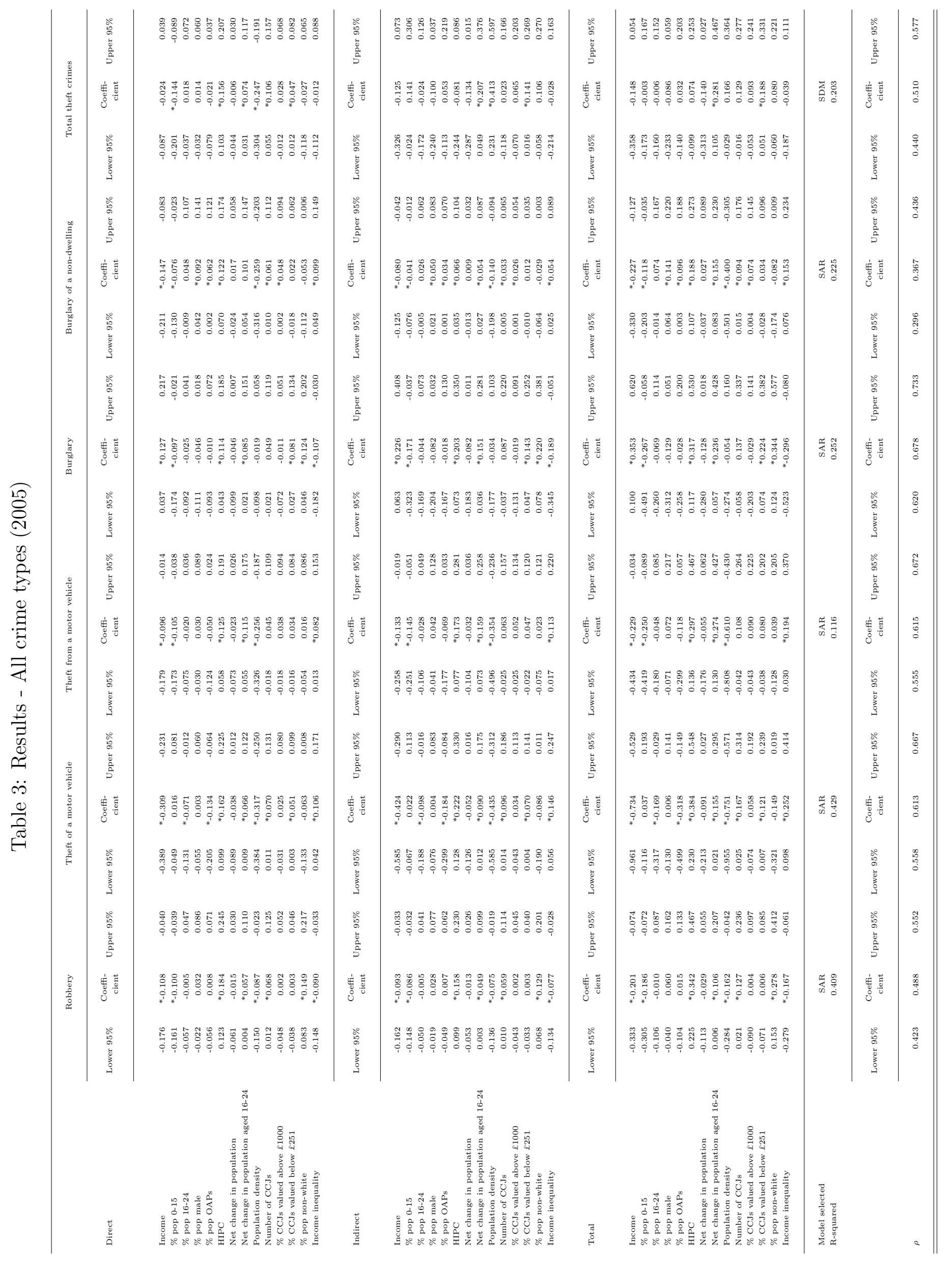




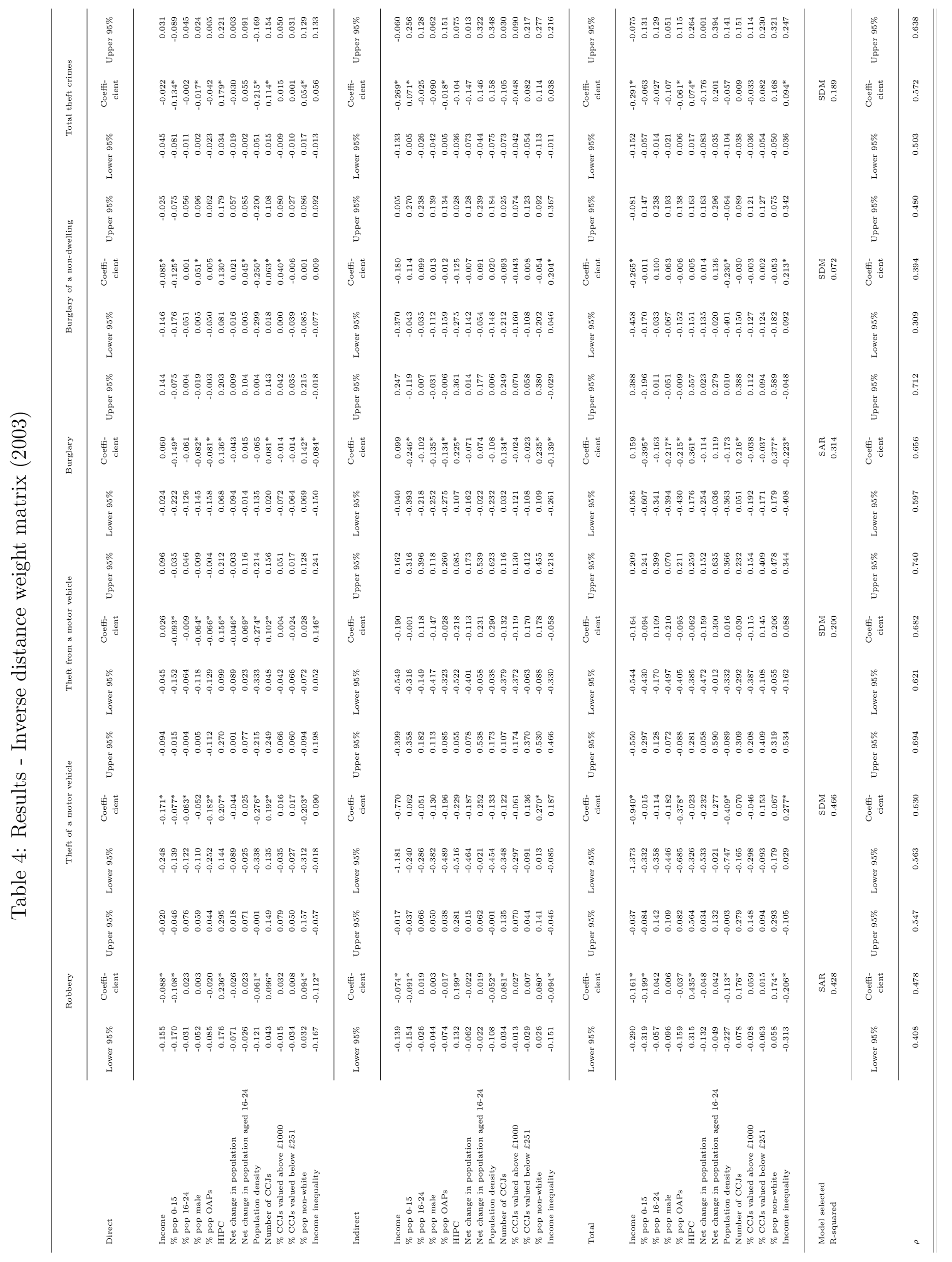

